\title{
Evaluating the Green Credentials of Flow Chemistry towards Industrial Applications
}

\author{
Marcus Baumann*a (iD) \\ Thomas S. Moodyb,c \\ Megan Smyth*b (D) \\ Scott Wharry \\ a School of Chemistry, University College Dublin, Science Centre \\ South, Dublin D04 N2E5, Ireland \\ marcus.baumann@ucd.ie \\ ${ }^{b}$ Department of Technology, Almac Sciences Ltd., 20 Seagoe \\ Industrial Estate, Craigavon BT63 5QD, UK \\ megan.smyth@almacgroup.com \\ tom.moody@almacgroup.com \\ 'Arran Chemical Company, Monklands Industrial Estate, Athlone, \\ Co. Roscommon N37 DN24, Ireland
}

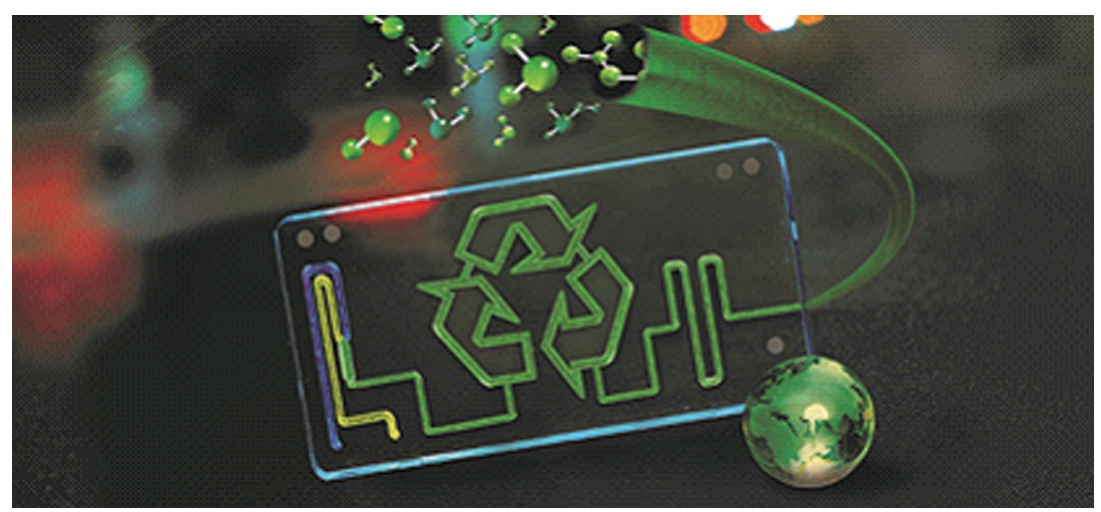

Received: 03.06.2021

Accepted after revision: 30.06 .2021

Published online: 30.06 .2021

DOI: 10.1055/a-1541-1761; Art ID: ss-2021-r0335-sr

License terms: CC)

(c) 2021. The Author(s). This is an open access article published by Thieme under the terms of the Creative Commons Attribution-NonDerivative-NonCommercial-License, permitting copying and reproduction so long as the original work is given appropriate credit. Contents may not be used for commercial purposes or adapted, remixed, transformed or built upon. (https://creativecommons.org/licenses/by-nc-nd/4.0/)

Abstract Continuous flow chemistry is becoming an established technology platform that finds frequent application in industrial chemical manufacture with support and endorsements by the FDA for pharmaceuticals. Amongst the various advantages that are commonly cited for flow chemistry over batch processing, sustainability continues to require further advances and joint efforts by chemists and chemical engineers in both academia and industry. This short review highlights developments between 2015 and early 2021 that positively impact on the green credentials associated with flow chemistry, specifically when applied to the preparation of pharmaceuticals. An industrial perspective on current challenges is provided to whet discussion and stimulate further investment towards achieving greener modern synthetic technologies.

1 Introduction

2 Subject Areas and Relevant Case Studies

3 Industrial Outlook on Future Sustainability Driven through

Continuous Manufacturing Approaches

4 Conclusions and Outlook

Key words flow chemistry, green chemistry, sustainable synthesis, process optimization, in-line purification, reaction telescoping

\section{Introduction}

Increasing pressures on efficiency, sustainability, and competitiveness is driving chemists in both academia and industry to continue to develop greener chemical synthesis and their associated technologies. In recent years technology-based solutions have played a major role for modernizing existing approaches and realizing new breakthroughs.
In this context, continuous flow chemistry has been receiving significant attention as it is considered to be a vital component towards achieving sustainable chemical transformations. Through miniaturization of reactor components, flow processes offer excellent heat and mass transfer which provides high levels of reaction control and process safety. ${ }^{1}$ In addition, flow processes can be automated and are based on modular small footprint reactors which offers flexibility and further opportunities for expanding the applications of related industrial continuous processes. ${ }^{2}$ As many flow routes demonstrate the effective integration of in-line analysis and various purification tools, time-consuming and labor-intensive offline downstream processing can be avoided. ${ }^{3}$ For these reasons flow chemistry is commonly assumed to contribute to greener synthesis of highvalue compounds. However, it could be argued that such a default position is not justified, and only deliberate efforts to combine continuous processing with modern sustainable chemistry approaches will result in meaningful advances towards reducing chemical waste and energy consumption.

Previous reports by Ley, ${ }^{4}$ Kappe, ${ }^{5}$ Jensen, ${ }^{6}$ and others ${ }^{7}$ have evaluated the prospects of flow chemistry to improve the greenness of chemical processes. This review covers a variety of reports published in the period 2015-early 2021 that highlight flow approaches that provide clear advantages in view of sustainability and additionally showcase their applicability in the chemical industries (pharmaceuticals, agrochemicals, polymers, etc.) where uptake is increasing following endorsement of the technology by regulatory bodies such as the FDA. ${ }^{8}$ Initial case studies will highlight the application of modern chemical synthesis based on photochemistry, electrochemistry, and biocatalysis, whereas subsequent examples discuss concepts such as catalyst immobilization, gas-liquid transformations, as well as reaction telescoping. An industrial perspective on these developments will provide context on the advances achieved 


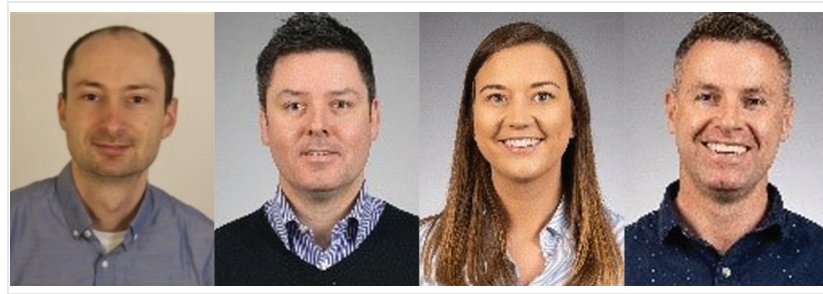

Marcus Baumann is Assistant Professor for Continuous Flow Chemistry at University College Dublin where his research group focuses on developing new continuous flow technologies for sustainable chemical synthesis including reaction scale-up, photochemistry, and biocatalysis. Marcus graduated from Philipps-University Marburg (2007) and received his Ph.D. from the University of Cambridge (2011) before doing postdoctoral research at the University of California Irvine (2011-2013) and Durham University (2013-2017). He currently holds an SFI Industry Fellowship intensifying research links with chemical companies specifically in modern continuous flow biocatalysis.

Thomas Moody is Vice President Technology Development and Commercialisation at Almac Sciences and Arran Chemical Company. He is responsible for driving new technology processes from conception to commercial scale-up across multi-disciplinary research including biocatalysis, flow chemistry, radiochemistry, custom synthesis, and commercial production. Tom holds a B.Sc. Chemistry 1st Class Hons.), Ph.D. (Organic Chemistry), and a Masters in Business with distinction in Business Strategy. His work has earned him numerous accolades and he is co-author of over 100 publications and patents. He is a strategic leader and technical expert with more than 18 years of extensive academic and industry experience.

Megan Smyth is Technical Leader within Almac Sciences. Megan graduated from Queen's University Belfast with 1st Class Hons. Chemistry (MSci) in 2012 before returning to obtain a Ph.D. graduating in 2016. Megan is responsible for the development of flow capabilities and delivery of projects for customers. Additional experience includes bioprocessing, technology transfer, and process scale-up

Scott Wharry is Custom and Flow Chemistry Manager at Almac Sciences. Scott completed his studies at Queen's University Belfast graduating in both 1994 (BSC) and 1998 (Ph.D. Organic Chemistry). Scott is responsible for continuous processes at Almac. He has over twenty years of experience managing multi-disciplinary teams across process development, technology transfer, and multi-kg GMP manufacturing. Additional expertise includes GMP manufacture and bioprocessing.

while identifying further requirements to realize supplementary sustainable chemical synthesis.

\section{Subject Areas and Relevant Case Studies}

\subsection{Photochemistry}

For over a century photochemistry has been recognized as a powerful means to synthesize target molecules by exploiting light. Ciamician, one of the pioneers of photochemistry, recognized at the dawn of the 20th century that lightdriven reactions hold great potential for future applications, ${ }^{9}$ however, it was not until recently with the advent of modern photoredox catalysis that the community intensified its efforts towards creating and exploiting a plethora of highly effective photochemical reactions. ${ }^{10}$ Continuous flow processing together with the availability of modern light-emitting diode technology thereby plays a key role in providing a suitable technology platform that overcomes inherent limitations of batch photochemistry relating to the insufficient penetration of light into reaction vessels (Beer's law). ${ }^{11}$ Specifically, flow processing offers short path lengths of light and thus uniform irradiation of microchips or tubular reactors in combination with excellent temperature and residence time control that avoid over-irradiation and related secondary photoreactions. Furthermore, scalability of continuous photochemical reactions is readily achieved via scale-up and scale-out approaches facilitating the production of kilogram quantities per day. ${ }^{12}$

The Minisci reaction plays a vital role in functionalizing heterocyclic scaffolds that are commonly encountered in medicinal chemistry programs. ${ }^{13} \mathrm{~A}$ continuous photochemical variant was reported in 2015/2016 by Stephenson and co-workers who opted to use trifluoroacetic anhydride as source of $\mathrm{CF}_{3}$ groups that would functionalize pyrroles in the presence of a ruthenium catalyst and 4-Ph-pyridine $\mathrm{N}$ oxide (Scheme 1). ${ }^{14}$ The decarboxylation of TFAA was triggered by blue LEDs rendering a variety of trifluoromethylated pyrroles (e.g., 2) in high yields. The flow approach was further optimized to reach throughputs of $20 \mathrm{~g} / \mathrm{h}$ allowing production of $950 \mathrm{~g}$ within $48 \mathrm{~h}$.

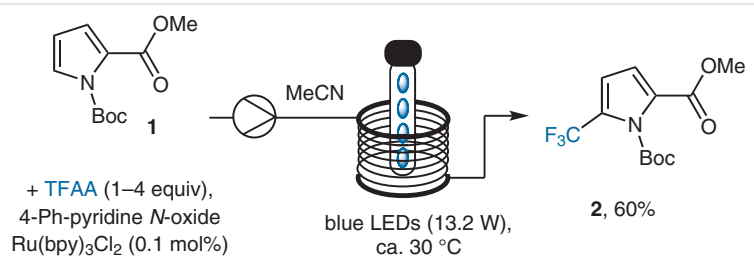

Scheme 1 Ru-catalyzed photo-trifluoromethylation

In 2017, the Nöel and Alcazar groups demonstrated an analogous Ir catalyst approach towards trifluoromethylated targets using sodium triflate under visible light irradiation. ${ }^{15}$ This approach tolerated various heterocyclic substrates (e.g., 3) allowing for rapidly accessing these important scaffolds for SAR studies without recourse to wasteful multistep sequences (Scheme 2).

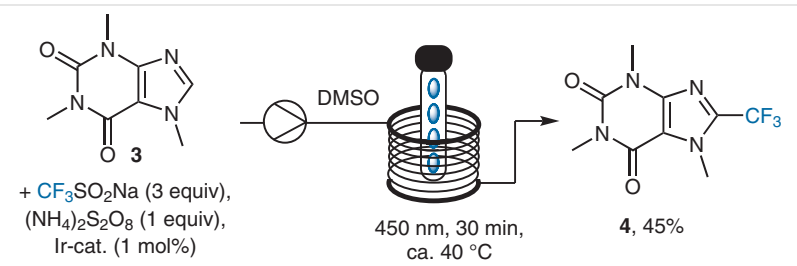

Scheme 2 Ir-catalyzed flow trifluoromethylation approach 
Photoredox catalysts based on Ru or Ir species are commonly used in modern photochemical applications. When used at low loadings ( $<0.5 \mathrm{~mol} \%)$ such processes are acceptable at small scale but could still raise concerns regarding cost and sustainability when scaled up. An alternative approach using organic photosensitizers such as $p$-terphenyl was reported in 2017 by the Jamison group for the $\beta$-selective carboxylation of simple styrenes (Scheme 3). ${ }^{16}$ This work highlights an attractive means to trap $\mathrm{CO}_{2}$ and create useful cinnamic acid building blocks in a direct one-step manner. The $\beta$-regioselectivity results from a single electron reaction pathway where the choice of amine reductant along with an excess of water were found to be critical. Crucially, these optimized conditions render a mild and effective process that uses unreactive $\mathrm{CO}_{2}$ gas at atmospheric pressure.

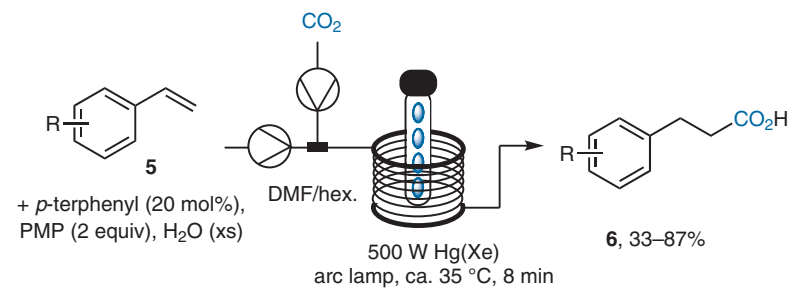

Scheme 3 Photochemical flow synthesis of cinnamic acids

The use of oxygen gas is frequently exploited in flowbased photo-oxidation processes. ${ }^{17}$ Organic photosensitizers such as Rose Bengal can be used in solution or on heterogeneous supports (i.e., packed bed reactor) to facilitate the oxidation of thioethers such as methionine, various ene reactions or more complex transformations as seen in the photochemical oxidation of artemisinic acid (7) to the antimalarial drug artemisinin (8; Scheme 4). ${ }^{17 \mathrm{~b}}$

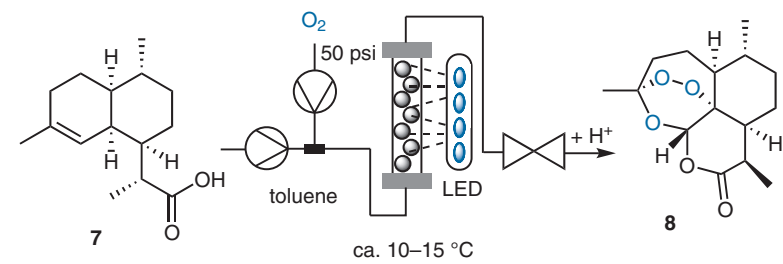

Scheme 4 Photo-oxidation towards artemisinin in flow

The ability to safely use oxygen gas or hydrogen peroxide as green oxidants was also reported by different research groups when developing continuous photochemical $\mathrm{C}-\mathrm{H}$ oxidation processes. Simple azacyclic substrates were subjected to $\beta$ - or $\gamma$-selective photo-oxidations in the presence of sodium decatungstate $(\mathrm{NaDT})$ as hydrogen atom transfer (HAT) catalyst under acidic conditions (Scheme 5). ${ }^{18}$ Analogously, tetrabutylammonium decatungstate (TBADT) was used to afford a series of ketones from activated and unactivated alkanes in the presence of oxygen gas and UV-A light (Scheme 5). ${ }^{19}$

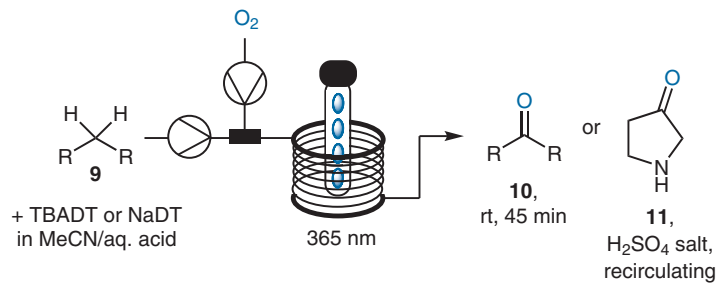

Scheme 5 Photo-oxygenations of $\mathrm{C}-\mathrm{H}$ bonds via HAT catalysis

The use of TBADT as a HAT catalyst in photochemical flow processes has since seen further applications in the preparation of versatile $\gamma$-aminopropyl sulfones ${ }^{20}$ as well as the powerful activation of unactivated gaseous hydrocarbon species. ${ }^{21}$

The above examples clearly demonstrate that the union of flow processing and photochemistry results in access to industrially important building blocks via green one-step routes that exploit catalysis (Ir/Ru, organic photocatalysts, or TBADT) to bring about the activation of stable entities using mild conditions and readily available reagents. The ability to use flow processing to generate valuable highenergy intermediates and convert these via photochemical reactions into prefunctionalized drug-like building blocks was demonstrated in 2021 by the Baumann group. The work details the continuous generation of [1.1.1]propellane and its subsequent reaction with mixed oxalyl chlorides to generate non-symmetrical bicyclopentane species (BCP, Scheme 6). ${ }^{22}$ Crucially, this flow process tolerates various alkyl ester moieties and conserves the acid chloride functionality thus enabling direct coupling reactions towards various BCP ester and amide products. Compared to previous methods to generate analogous products from diacetyl and [1.1.1]propellane, this new approach is a single-step process and thus avoids time- and waste-intensive multistep sequences.

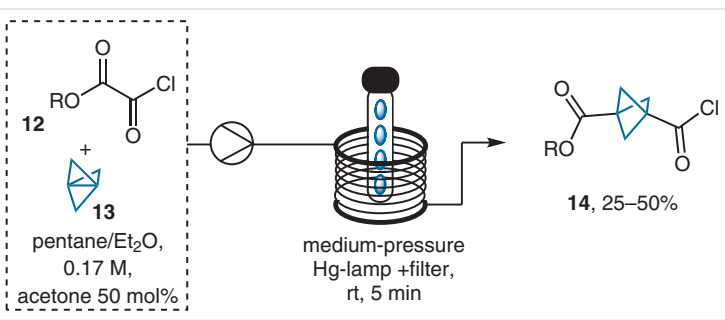

Scheme 6 Photochemical synthesis of non-symmetrical BCPs 


\subsection{Electrochemistry}

Electrosynthesis is undergoing the same revival that was discussed earlier for photochemical transformations. Key drivers are the development of more sustainable chemical processes, where stoichiometric reagents can be replaced by electricity as a clean and readily available reagent equivalent. Conceptually, electrochemistry can be applied to a plethora of redox processes and a significant number of classical transformations can be targeted. ${ }^{23}$ With the advent of new commercial equipment for conducting electrosynthesis in batch and flow mode, a significant barrier for running these reactions has now been overcome allowing chemists to quickly set up and optimize electrochemical reactions. In addition, flow processing is an automatable technology that increases mass transfer and facilitates subsequent scale up. Recent reviews by Nöel ${ }^{24}$ and $\mathrm{Lam}^{25}$ have highlighted the potential of flow electrochemistry for cleaner chemical synthesis in academic and industrial settings.

In 2017, the Wirth group demonstrated the use of a simple to manufacture flow reactor to create a set of isoindolinone products by electrochemical $\mathrm{C}-\mathrm{N}$ bond formation (Scheme 7). ${ }^{26}$

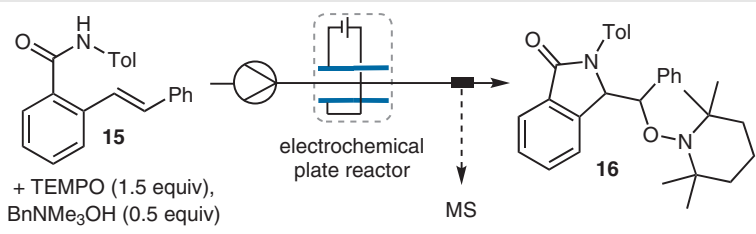

Scheme 7 Electrochemical synthesis of isoindolinones

This is an attractive approach as it renders the desired products in high yields with minimal use of supporting electrolyte. TEMPO is oxidized in situ prior to converting an amide $\mathrm{N}-\mathrm{H}$ bond into its corresponding nitrogen-centered radical which then undergoes cyclization with a pending alkene and subsequent trapping with the reduced form of TEMPO. Subsequent cleavage of the $\mathrm{N}-\mathrm{O}$ bond using zinc powder in the presence of HOAc was demonstrated via a telescoped flow protocol and showcases the rapid generation of the heterocyclic targets.

In a related study the same group reported an electrochemical process converting $N$-benzoylated proline species (e.g., 17) via $\mathrm{N}$-acyliminium ions into enantioenriched $\alpha$ alkoxyamines. ${ }^{27}$ This process is based on a non-Kolbe electrolysis and features memory-of-chirality stemming from the original amino acid. The report furthermore details exploitation of DOE and online 2D-HPLC techniques to expedite the optimization process resulting in the green synthesis of several useful building blocks (Scheme 8). Although reported ee's do not exceed $70 \%$, this electrochemical pro- cess is a useful addition to flow-based methods exploiting memory-of-chirality, which previously were conducted via cryogenic lithiation processes. ${ }^{28}$
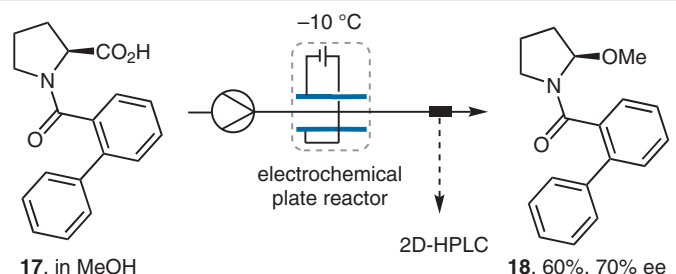

Scheme 8 Non-Kolbe electrolysis in flow mode

The power and elegance of flow electrosynthesis was demonstrated in 2019 by the Nöel group by generating a variety of medicinally relevant sulfonamides. ${ }^{29}$ The use of electrochemistry avoided the use of activated substrates (e.g., sulfonyl chloride) and bases as common stoichiometric reagents, thus contributing to a more sustainable approach. This work highlights the oxidative transformation of thiols and disulfides in the presence of primary or secondary amines to generate the sulfonamide product (e.g., 21) via sulfenamide and sulfinamide intermediates (Scheme 9).

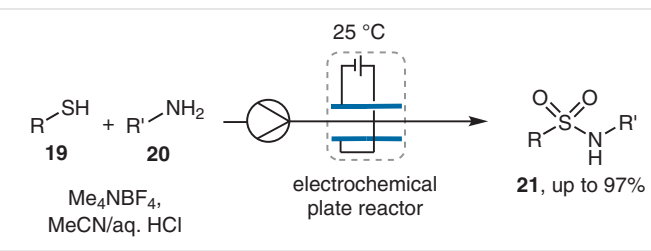

Scheme 9 Continuous electrosynthesis of sulfonamides

A further application of continuous electrochemistry that showcases its potential for greener building block assembly concerns the generation of biaryls by dehydrogenative coupling of phenols. This report was published in 2019 by the Waldvogel group and highlights a flow process that uses a pyridine/hexafluoroisopropanol (HFIP) solvent system in lieu of a support electrolyte (Scheme 10). ${ }^{30} \mathrm{~A}$ bespoke electrochemical reactor was manufactured that enables the safe removal of the gaseous hydrogen byproduct and reaches productivities of $9.6 \mathrm{~g} / \mathrm{h}$ thus demonstrating the potential for scaling this transformation.

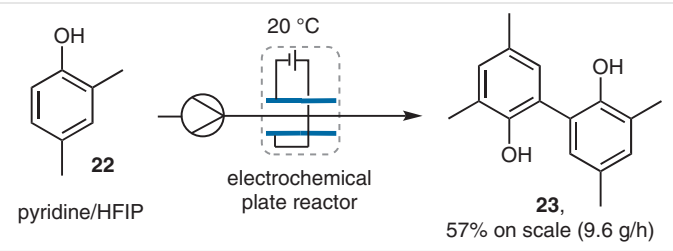

Scheme 10 Dehydrogenative coupling of phenols in flow 


\subsection{Biocatalysis}

The use of enzymes as highly selective catalysts that facilitate a variety of important chemical transformations under mild conditions and in benign solvent systems is the key driver behind the increasing use of biocatalysis in organic synthesis. As mass transfer in batch-based approaches can be limited, continuous flow biocatalysis ${ }^{31}$ has emerged as a new field in recent years where both solution phase and immobilized enzymes are exploited. As highlighted in previous reviews, the use of transaminases is of particular interest in such flow approaches as it allows for the facile generation of chiral amines that serve as versatile building blocks and feature in many modern drugs. ${ }^{32}$

Immobilization of enzymes is a general and widely exploited strategy as it allows for using the resulting heterogeneous biocatalysts in packed bed reactors which provides facile separation, high mass transfer and in many cases increased stability of the biocatalyst. As the immobilization process can be challenging and can require bespoke procedures and polymer backbones, new and straightforward alternatives are necessary to facilitate the expansion of this field. ${ }^{33}$ One approach reported in 2019 by Luo and co-workers describes the use of a monolithic biopolymer based on cellulose acetate. ${ }^{34}$ This system offers a well-defined structure with interconnected pores and immobilization of enzymes such as lipases was readily achieved by passing a buffered solution of the enzyme through the monolith. In a long-time application the resulting monolith was then used over $200 \mathrm{~h}$ to affect the esterification of a phytosterol (Scheme 11). Importantly, the resulting flow process consistently rendered yields of $>93 \%$ and increased the efficiency by $66 \%$ compared to an analogous batch process.

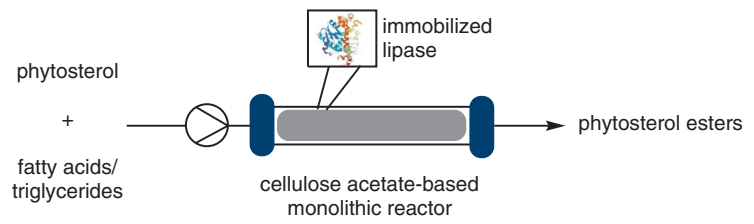

Scheme 11 Monolithic biopolymers for biocatalysis in flow

A similar approach was demonstrated in 2020 by Chanana and co-workers who used poplar wood as a source of a monolithic support for various enzymes. To exploit the porous nature of this support material, the authors first impregnated this with a solution of chloroauric acid leading to reduction of gold by the lignins. The resulting gold nanoparticles then allowed for facile absorption of various enzymes upon passing of buffered solutions through the monolith before use in different flow applications. ${ }^{35}$

With the number of flow-based applications of biocatalyzed transformations on the rise, researchers are also turning their attention to use enzymes for downstream processes to realize simpler and greener workup and purification.
In a 2021 study this concept was demonstrated for the removal of benzyl alcohol in telescoped flow Curtius rearrangements. ${ }^{36}$ The requirement for excess benzyl alcohol $(\mathrm{BnOH})$ (which cannot be evaporated easily) resulted in a product contaminated with $\mathrm{BnOH}$ and utilization of a packed-bed reactor containing immobilized Candida antarctica lipase b (CALB) in combination with vinyl butyrate to derivatize $\mathrm{BnOH}$ into benzyl butyrate and acetaldehyde. Importantly this circumvented the need for column chromatography in favor of a simple trituration to isolate the target Cbz-carbamate products (24, Scheme 12$)$.

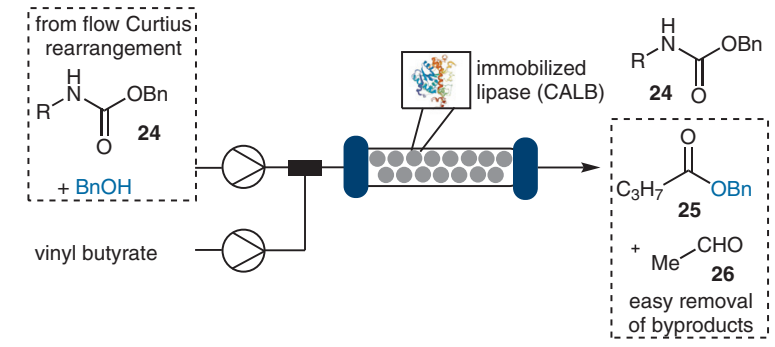

Scheme 12 Impurity tagging via CALB cartridge reactors

\subsection{Reaction Telescoping}

The ability to link individual flow reactions into telescoped sequences is of fundamental importance to not only increase the efficiency of the process, but also to minimize and avoid contact of the operator with harmful intermediates. In addition, as in-line purification tools can be employed to remove byproducts and other detrimental impurities, traditional off-line purification can be either avoided or minimized which positively impacts the sustainability of such flow processes. Although not trivial, the development of effective telescoped flow sequences has gained significant attention and has been reviewed recently. ${ }^{37}$ Not surprisingly, further efforts are underway in both academia and industry to realize robust and general approaches towards flow-based reaction telescoping.

Work in 2017 from the Jamison group showcased the power of reaction telescoping for the synthesis of a series $\mathrm{CF}_{3}$-substituted pyrazoles and pyrazolines through [3+2]dipolar cycloaddition chemistry. ${ }^{38}$ Specifically, this application details the generation of (trifluoromethyl)diazomethane (29) via diazotization of the corresponding amine with tert-butyl nitrite. This reactive intermediate is then subjected to thermal cycloaddition reactions with different dipolarophiles followed by various derivatization reactions in flow mode (Scheme 13). Finally, off-line purification furnished these medicinally relevant targets (e.g., measles therapeutic AS-136A, 32) in good yields. This application demonstrates that fully telescoped processes are viable yet prone to give lower yields due to interfering byproducts. Removal through in-line purification strategies can be challenging and may result in a less sustainable overall process- 
es due to larger amounts of solvents and other reagents being deployed.

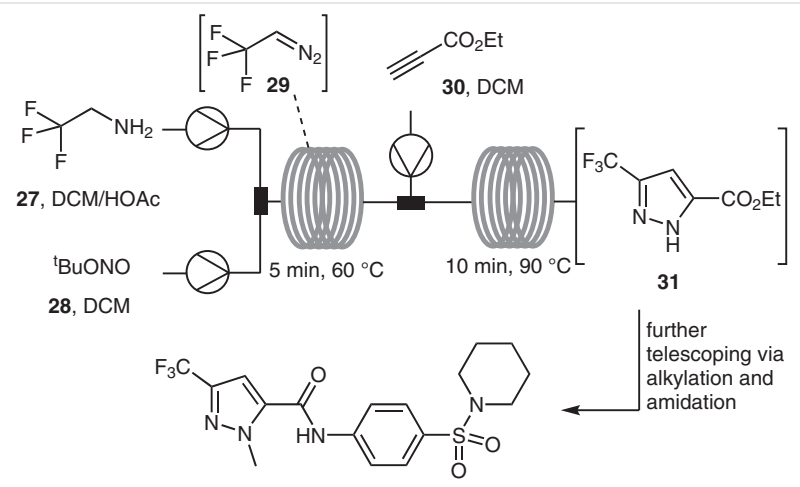

32, AS-136A; fully telescoped: $34 \%, 1.73 \mathrm{~g} / \mathrm{h}$

Scheme 13 Telescoped synthesis of $\mathrm{CF}_{3}$-substituted pyrazoles

Related work by Jamison, Jensen, and co-workers expanded on this theme through demonstrating a telescoped flow protocol for the synthesis of ciprofloxacine sodium salt (41).$^{39}$ Crucial to realizing this fast and effective flow process devoid of any intermediate isolations or purifications was the judicious choice of reaction conditions including solvents and concentrations to avoid problems in relation to precipitate formation. In addition, it was found that dimethylamine, generated as a byproduct, needed to be converted by acetylation into innocuous dimethylacetamide (38; Scheme 14) prior to a downstream $S_{N} A r$ reaction involving piperazine. Treatment of the sodium salt of ciprofloxacine with $\mathrm{HCl}$ was performed off-line generating the corresponding $\mathrm{HCl}$ salt in $60 \%$ yield.

A 2019 report by Monbaliu and co-workers demonstrates the efficient flow synthesis of ketamine (45) via a telescoped three-step sequence. ${ }^{40}$ Key to the success of this approach was also the careful choice of solvents and additives to circumvent commonly encountered bottlenecks. Ethanol was therefore exploited as the sole solvent for all steps and appropriate additives such as PEG-400 used to solubilize $\mathrm{KOH}$ in the oxidative hydroxylation step (Scheme 15). Triisopropyl borate (43) was chosen as a readily soluble Lewis acid to facilitate imine formation before a packed-bed reactor filled with montmorillonite K10 triggered the ring expansion process at high temperature. $\mathrm{HCl}$ salt formation was subsequently performed off-line to afford the active pharmaceutical ingredient (API) as a crystalline material in high yield (up to $62 \%$ ).

The previous examples highlighted the importance of matched reaction conditions (reagents, solvents, concentrations, etc.) for the success of telescoped reactions that are based on thermal processes. A 2020 study by the Baumann group additionally demonstrates how photochemical flow processes can be integrated into telescoped sequences exploiting high-power LEDs emitting in the UV-A region (ca.

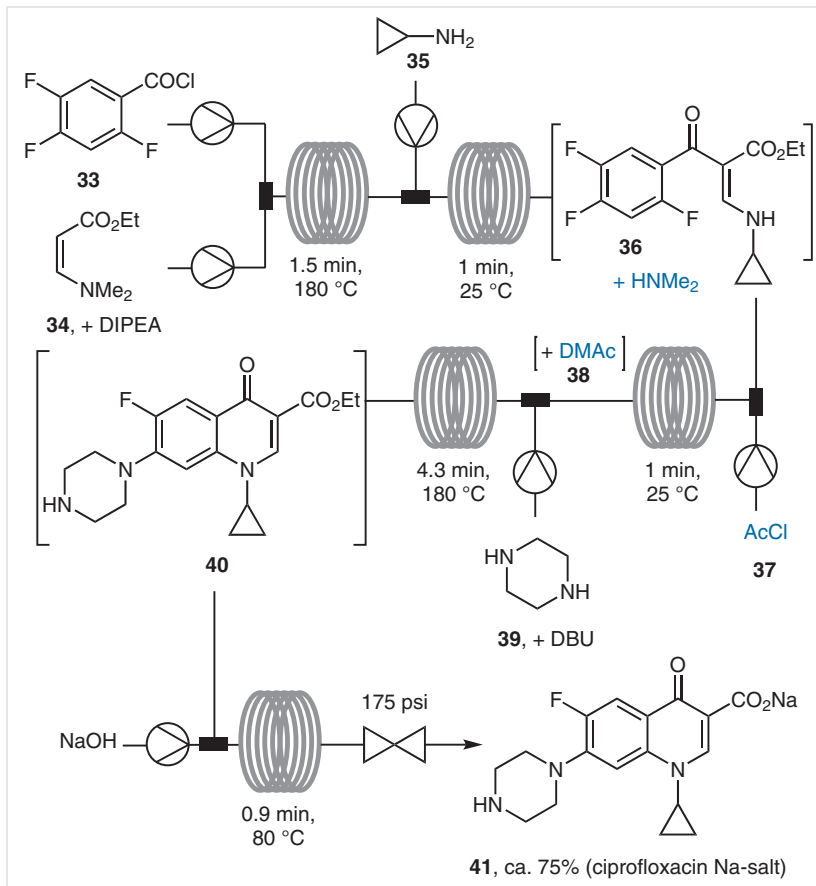

Scheme 14 Telescoped flow synthesis of ciprofloxacin Na salt

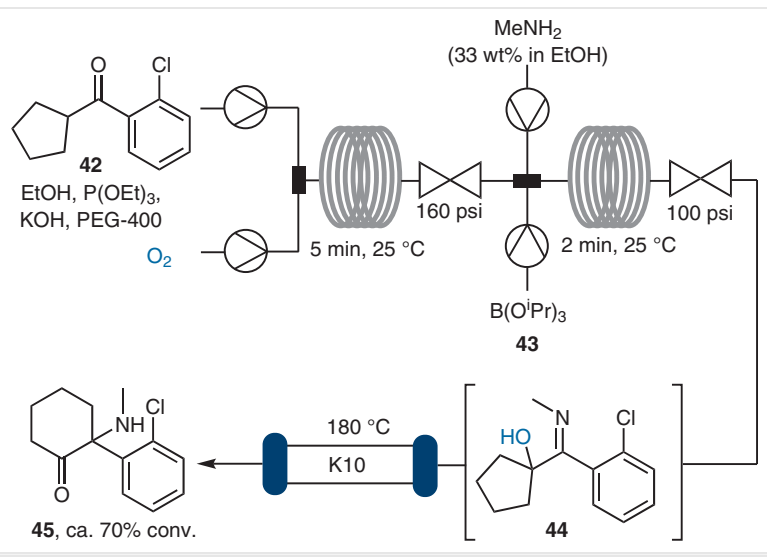

Scheme 15 Telescoped flow synthesis of ketamine

$365 \mathrm{~nm}) .^{41}$ This alleviated requirement for a classical medium-pressure Hg lamp that often is prone to generate multiple side-products which in turn can hamper downstream reactions. In this specific application, photoisomerization of an enone moiety was triggered by the LED facilitating condensation with a strategically placed amine group to afford a series of quinoline products (Scheme 16). Due to the excellent wavelength match of the lamp emission with the substrate absorbance, side-product formation was drastically reduced allowing for the direct hydrogenation of these intermediates using an $\mathrm{H}-\mathrm{Cube}^{\mathrm{TM}}$ flow reactor without poisoning the Pd catalyst. This process rendered a series of drug-like tetrahydroquinolines including the antimalarial 
compound galipinine (48) in high chemical yields and excellent purity.

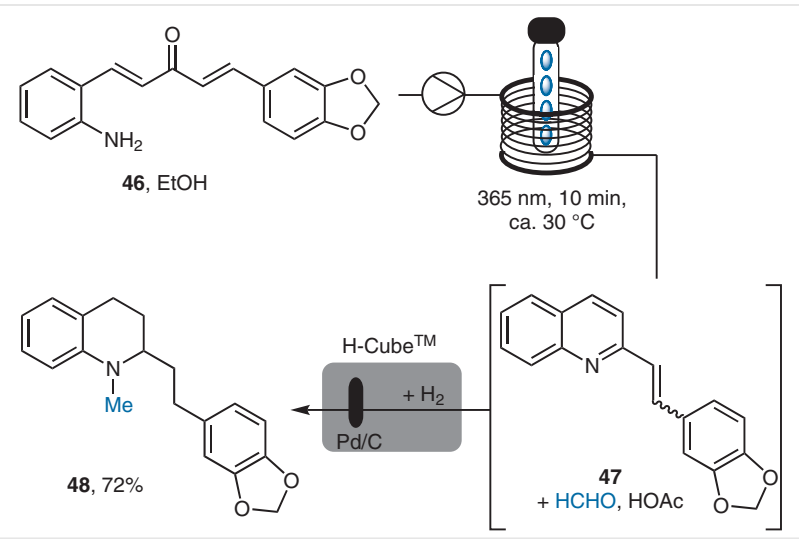

Scheme 16 Synthesis of quinolines and reaction telescoping towards tetrahydroquinolines in flow

\subsection{Gas-Liquid Reactions}

The reaction between reactive gases with solutions of substrate in the presence of appropriate catalysts is a valuable strategy within synthetic chemistry to build more complex products. Safety concerns along with inefficient mixing between the liquid and gas phase, hampers the effective execution of these gas-liquid transformations in batch mode. Flow processing provides a powerful means to overcome these limitations as summarized in recent reviews. ${ }^{42}$ From a sustainability perspective, oxygen and hydrogen gas are the most exploited reactive gases in synthetic chemistry and hence they are highly relevant for industrial applications. The effective use of oxygen in photochemical processes was already highlighted in the photochemistry section where flow processing further aided in overcoming issues in relation to uniform irradiation as well as the otherwise limited mass-transfer of oxygen gas into the reaction solution. A further example by Chalker and Raston highlights the use of a vortex reactor for oxidative transformations. ${ }^{43}$ This type of reactor is based on a rapidly rotating quartz tube in which a thin film of the substrate solution increases mixing with gaseous oxygen. Reagent solution is thereby continuously pumped into the vortex reactor whose rotational speed and tilt angle can be adjusted easily. This was demonstrated in the aerobic oxidation of $\mathrm{N}$-acetyl-L-cysteine (49) rendering the corresponding disulfide species in quantitative yield in only 2.5 min residence time, whereas batch processing required reaction times in the order of hours (Scheme 17).

Yu and co-workers reported on a kilogram-scale synthesis of a benzoic acid target using oxygen gas in continuous flow-mode. ${ }^{44}$ 2,4-Dichloro-5-fluoroacetophenone (51) was thereby used as a readily available substrate to generate the corresponding acid $\mathbf{5 2}$ which is a valuable building block in pharmaceutical and agrochemical syntheses. To replace en-

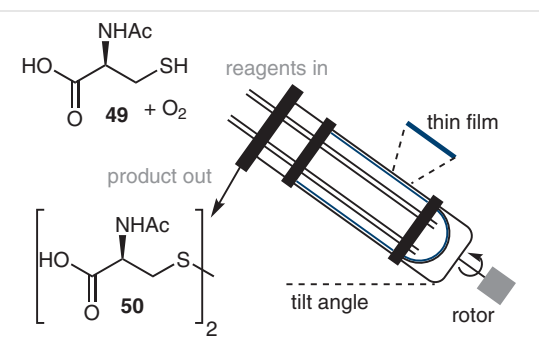

Scheme 17 Oxidative dimerization of thiols in vortex reactor

vironmentally problematic oxidants, oxygen gas was exploited in tandem with flow processing to overcome masstransfer limitations whilst providing a safe and scalable technology for this exothermic process. The flow process accommodated the use of the hazardous solvent system $\left(\mathrm{HOAc} / \mathrm{HNO}_{3}\right)$ to provide the desired acid product in near quantitative yield by crystallization upon cooling. In addition to significant throughput $(2.7 \mathrm{~kg} / \mathrm{h})$, this process integrated continuous venting of the crude mixture with nitrogen gas before collecting the reaction mixture in a collection tank to remove oxygen gas (Scheme 18).

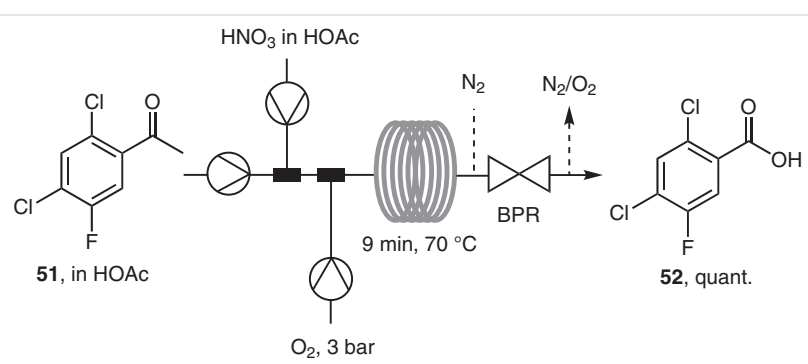

Scheme 18 Continuous aerobic oxidation of 2,4-dichloro-5-fluoroacetophenone

Analogous hydrogenation reactions are highly relevant in industrial environments to affect the saturation of a variety of substrates in the presence of suitable catalysts. Apart of improving the safety through flow processing, such endeavors aim to minimize chemical waste and realize robust and scalable entries into important building blocks. In 2020, Kobayashi and Saito reported on an asymmetric hydrogenation of enamides $\mathbf{5 3}$ and dehydroamino acids exploiting an immobilized Rh catalyst. ${ }^{45}$ The immobilization of this species was thereby based on ionic and electrostatic interactions with amine-functionalized mesoporous silica composites which provided high turnover numbers and long-term stability. A variety of substrates were successfully converted into their saturated counterparts under mild conditions $\left(\mathrm{T}=30^{\circ} \mathrm{C}\right)$ tolerating labile nitro groups as well as halogens. The resulting flow process was furthermore exploited in the synthesis of various drug precursors (e.g., rivastigmine, tecalcet, and cinacalcet) and demonstrated for 
continuous campaigns up to $90 \mathrm{~h}$ without loss of the catalyst's activity (Scheme 19).

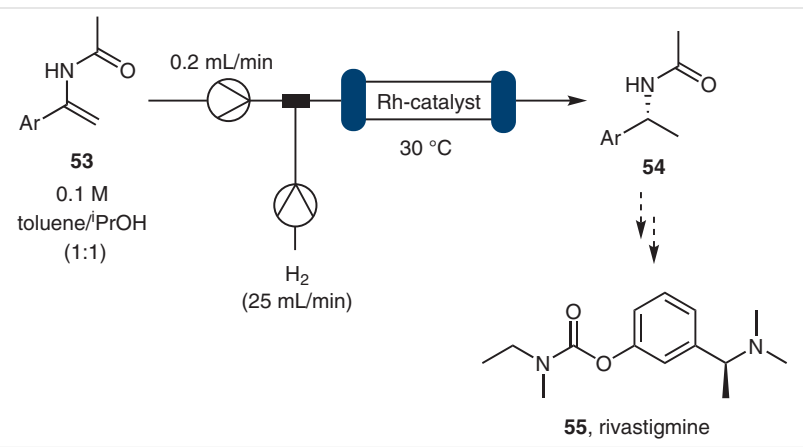

Scheme 19 Asymmetric hydrogenation in flow mode

A further example demonstrating advances in flow processing in view of improving the sustainability of the corresponding transformation concerns the reduction of esters to alcohols. Conventionally, $\mathrm{LiAlH}_{4}$ is used as a stoichiometric reagent which produces significant amounts of inorganic waste products. Kappe and co-workers turned to using Ru-Macho as a highly effective homogeneous catalyst in combination with hydrogen gas under elevated pressure (20 bar). ${ }^{46}$ The resulting flow process was applied to the synthesis of 2,2-difluoro-2-phenylethanol (57), an important intermediate in the pharmaceutical industry (Scheme 20). Low catalyst loadings $(0.065 \mathrm{~mol} \%)$ in combination with a moderate temperature of $60{ }^{\circ} \mathrm{C}$ afforded the product in $98 \%$ yield. Importantly, reduction of the process mass intensity from previously 52 to 14 was achieved, clearly demonstrating the green credentials of suitably optimized transformations in combination with modern flow processing.

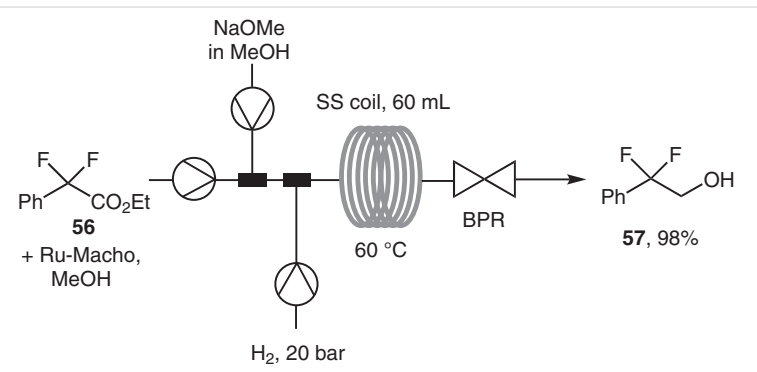

Scheme 20 Ru-Macho catalyst for reduction of esters in flow

\section{Industrial Outlook on Future Sustainabili- ty Driven through Continuous Manufacturing Approaches}

\subsection{Complexity of Change}

The complexity and rate of change of business environments within which organizations operate means that a re- liance on trend analysis and predicted projections is no longer enough to guarantee future success. Businesses can no longer rely on traditional 'predict and control' strategies as in many cases the unstable, turbulent, novel, and ambiguous macro environments can directly impact company trajectory within their respective industry. From a sustainability perspective, it could be argued that the pharmaceutical industry has not historically prioritized sustainability as their key target or objective. The priority for this industry is to supply lifesaving drugs, of which in many cases the products are of high value and the long-term consequences of manufacturing them (manufacturing cost, waste control, supply chain ethics, etc.) was possibly deemed to be of lesser importance. Across multiple industries there have been concerns that increased regulations and government control could have direct consequences in profits which puts direct pressure of reinvestment of these profits which funds organizational R\&D spend. As such, some view this potential threat to revenue as a threat to public health.

Resistance to change is commonplace in many industries and is certainly no different in the fine chemical and pharmaceutical industry. With the increasing pace of technological development and competitor implementation, it is imperative for organizations to continue to be innovative, have the ability to adapt and be at the forefront of advancements for streamlined and sustainable chemical manufacture. Often the adoption of continuous flow can be restricted simply due to ambitious timelines set by the industry and the fact that often a redesign of the chemical process is necessary and not conducive to the already filed process.

\subsection{Multidisciplinary Innovation}

Innovation occurs at the interface of different disciplines and the continuous flow insurgence is no exception. Before moving from a typical batch to flow methodology, a critical evaluation of the chemistry is needed to determine if there is an advantage (cost analysis, suitability of process in flow, and can change be tolerated, etc.) to redeveloping an established process. Utilizing continuous flow technology can offer a robust and reliable process facilitating tighter process control resulting in more consistent yields and higher purities of isolated product. The industry needs demonstration of the significant economics to lower the cost of production compared to batch and an understanding of speed to market with generation of in-house case studies critical to support any organizations continued uptake. To develop continuous processes, for most organizations, this can require major cash investment, and therefore direct return on investment evidence is key to allow the business to implement the change. Drivers for the move from batch to flow include a reduction in capital expenditure (CAPEX) and operating expenses (OPEX) with a clear increase in process safety and product quality. 


\subsection{Supply Chain Governance}

The regulators are supportive partners to industry for the adoption of innovative manufacturing approaches through collaboration. Continuous approaches can help in the drive to ensure novel, improved technologies to improve supply chain resilience, Net Zero Impact, and to ensure continued growth of the manufacturing sector. Supply chain dependence has long been known to be on the critical path for western pharmaceutical manufacturers as legislation tightens in Asia, but it has become more apparent since the onset of the COVID pandemic. Critical delays in supply of raw materials have highlighted the need to back integrate manufacturing supply chains to ensure competitive advantage through internal control of manufacture for key raw materials. It is very important to stress and to realize that technology will not remove issues encountered with supply chains or yield tighter control over key raw materials. What technology can do, is open new supply chains and access to raw materials with securer and more mature options. Due diligence on selection of raw material providers and control of quality is critical. The use of technology should aid in the supply chain decision making to make sure that multiple companies can make the raw material, have the associated financial and government stability, and have appropriate safety and all of the required REACH credentials. ${ }^{47}$ Unexpected delays in critical raw material supplies can have significant knock-on effects across multiple projects/sites and products. Interruption to transport links, in particular shipping, observed during this COVID pandemic has resulted in many chemical manufacturers facing severe commercial challenges to maintain customer contracted supplies. It has highlighted the need to ensure robust supply chains are now put in place with immediate focused action plans deployed to ensure alternative manufacturing options for critical building blocks are realized to safeguard supply. Flow chemistry technology is proving to be an important contributor in the action plans for the subsequent green manufacture with reduced cost even when these chemical products are re-shored.

\subsection{Changing Skillsets To Embrace Change}

Currently most skillsets within the pharma and fine chemical industry will be batch centric. For flow chemistry to be adopted a mind-set change is needed when performing both retrosynthetic analysis and process design. Flow chemistry is reliant on multidisciplinary teams which is not always readily available in chemical companies. With the adoption of artificial intelligence (AI) the pharma industry is set to become smarter and more automated. ${ }^{48}$ In order to capture the added value from AI both the front-end technologies and back-end systems must be upgraded to allow organizations to process and understand the data gathered. This is a core competency for the future of pharma and will see an increase in computational scientists outside the field of academia and statisticians/mathematicians working within the industry ${ }^{49,50}$

With manufacturing on demand (ability to manufacture specific volumes anywhere at short notice) set for a meteoric rise the ability to form effective partnerships globally will be essential and a prerequisite. Partnerships will also be essential between academic and industrial organizations to deliver the training and skills necessary to secure a pipeline of highly skilled and talented individuals that can implement and deliver the changes required to be successful. Two such examples of effective partnerships include Continuous Manufacturing and Advanced Crystallisation (CMAC) at the University of Strathclyde and CC FLOW at the University of Graz. CMAC has built an industry led collaboration which is delivering an impactful and ambitious research programme. The sustainable success of the programme is inherently linked to the research excellence and outstanding skills development, establishment of world class facilities which promote exemplary translation to industry for main partners such as AstraZeneca, GSK, Novartis, Bayer, Eli Lilly, Takeda, Roche, and Pfizer supported by Tier 2 technology companies. By engaging with the broader industry landscape through open events encourages collaboration across a wide range of companies locally, nationally, and globally. In Graz, CC Flow focuses on the generation of both expertise and suitable technology to support continuous approaches for the manufacturing of APIs through process simplification, intensification, and integration to achieve cost-effective manufacturing. Pharmaceutical companies such as AstraZeneca, Eli Lilly, and UCB input to the consortium alongside equipment and technology providers for lab scale (ThalesNano) and industrial scale (Chemtrix). The major advantage of such consortiums is the collaborative approach accelerating the development of industrially relevant flow manufacturing capabilities. Education plays a critical role in the successful exploitation of flow chemistry. The discipline appears a simple concept on paper however, a key understanding of the fundamental principles from both a chemistry and chemical engineering perspective is of the utmost importance. Engaging with partners and forming collaborations will undoubtedly accelerate development and circumvent the common pitfalls and hurdles from which others have already taken key learnings.

The adoption of continuous flow within the industry is often driven by green metrics. ${ }^{51}$ Process Mass Intensity (PMI) and E-factor are two of the most favored approaches to determine the environmental sustainability of a process. ${ }^{52} \mathrm{PMI}$ is defined as the total mass of material to produce a specific mass of product. PMI focuses on process efficiency and is often deemed a more holistic approach to the implementation of green and sustainable technologies, with a consideration of reactants, solvents, and reagents used rather than simply a consideration of waste as seen with the E-factor. ${ }^{53,54}$ 
From sustainability perspective the benefits are typically considered under two key attributes; environmental and economic..$^{55}$ From an environmental perspective flow can reduce environmental burden with less byproduct formation, processes can be run more concentrated thus reducing solvent volumes, and offers the opportunity to run catalytically, reduce stoichiometry, or recycle. With the incorporation of process analytical technology (PAT) there is reduced potential for batch failure/waste due to out of specification material and the risk to operators is reduced due to smaller volumes of hazardous reagents reacting at any one time (less risk of release/explosion/fire). Considering an economic perspective cost savings can be achieved from getting 'more from less' in terms of atom economy, reducing the capacity requirements (if higher output targets can be achieved from better levels of conversion/yields). Higher efficiency can be achieved through better selectivity and fewer operations.

\subsection{Industrial Examples}

Several continuous flow examples are reported in the literature where the PMI has been considered and the effect of adopting continuous flow assessed. One example from the team at Idorsia ${ }^{56}$ reported an automated, scalable flow approach for the introduction of trifluoromethyl groups on a variety of heterocycles (e.g., 61-63). Heterocycles are relevant molecules within the pharma industry with the motif providing improved protein interaction and enable the modulation of physicochemical properties. ${ }^{57,58}$ Preparation of heterocycles, although essential, often are subject to long reaction times, high temperatures, and low isolated yields. ${ }^{9}$ This methodology (Scheme 21) involves the direct acylation-cyclization of amines in the presence of trifluoroacetic acid or anhydride which are cheap and readily available $\mathrm{CF}_{3}$-containing building blocks. The batch process involved an essential purification step which was circumvented using a continuous flow reaction which under mild conditions gave higher yields. It was also noted that the flow reaction methodology tolerated different functional group variance.

Initially the two-step batch process (involving trifluoroacetamide formation followed by dehydrative cyclization) was converted to flow. The process required an intermediate workup and purification by column chromatography but with a strategic goal to increase safety margins the reaction was developed in a single step using TFAA as both the $\mathrm{CF}_{3}$ source and the dehydrative cyclization reagent. ${ }^{60}$

An estimation of the green metrics including PMI and Efactor are reported in Table 1. The continuous-flow one-pot approach was more sustainable and cost effective than the two-step flow and two-step batch processes. The improvement is due to the removal of the intermediate workup op-

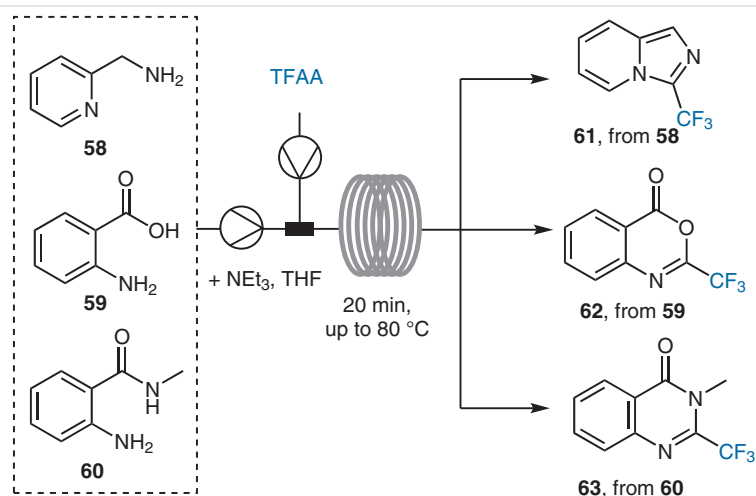

Scheme 21 Flow based synthesis of heterocycles

eration and introduction of a one-pot approach to the desired heterocycle. Process step complexity was reduced resulting in a more efficient and simplified synthetic procedure.

Table 1 Comparison of Reaction Yield, PMI, and E-Factor for a Flow and Batch Process for the Synthesis of Trifluoromethylated Heterocycles (Compound 61)

\begin{tabular}{llll}
\hline Metrics & One-pot flow & Two-step flow & Two-step batch \\
\hline Overall yield & $57 \%$ & $51 \%$ & $13 \%$ \\
PMI & 183 & 496 & 1728 \\
E-factor & 182 & 496 & 1727 \\
\hline
\end{tabular}

A further example from Merck ${ }^{61}$ came in 2020 with a report of the commercial manufacturing route to gefapixant citrate (73) from commodity materials as shown in Scheme 23 below. The original synthetic route is shown in Scheme 22 which was a linear 11 step synthesis, with a high PMI of 366, a low yield of $16 \%$ and a high API cost. ${ }^{62}$

The PMI was improved to 78 which was a 5 -fold increase compared to the original route. The yield was increased from $16 \%$ to $60 \%$ and a 6 -fold reduction in API raw material cost reported. Critically two highly toxic and hazardous chemicals $\left(\mathrm{POCl}_{3}\right.$ and $\mathrm{HOSO}_{2} \mathrm{Cl}$ ) and the hazardous alkylation was replaced to yield a more robust and safer process. Key highlights from the updated synthetic approach included:

(1) The implementation of a highly efficient two step synthesis to the methoxyphenol.

(2) The innovative diaminopyrimidine synthesis using a hybrid batch-flow process.

(3) A simplified direct sulfonamide synthesis.

(4) A novel, robust salt metathesis approach to deliver the correct API salt form in high purity as demonstrated to deliver $>300 \mathrm{~kg}$ of gefapixant citrate (73; Scheme 23). 
Original Synthetic Route
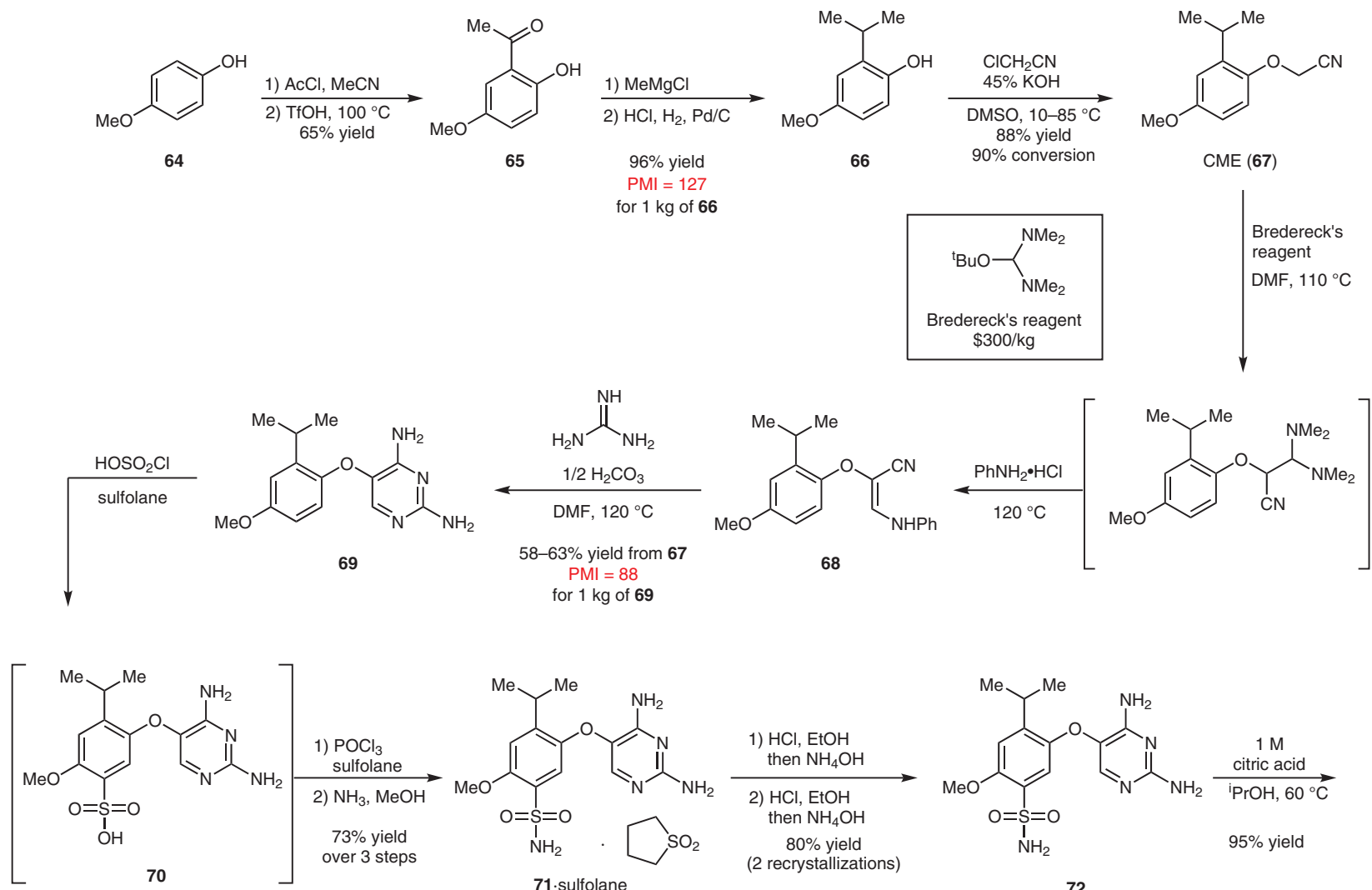

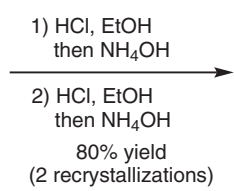

71.sulfolane

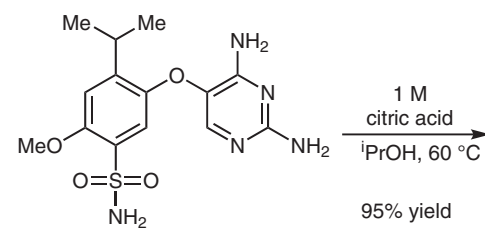

72

Scheme 22 Original route towards gefapixant citrate

New Commercial Process

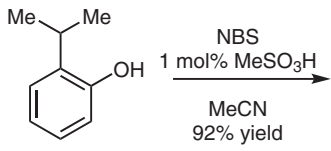

74

Step PMI $=9$<smiles>CC(C)c1cc(Br)cc([18O])c1O</smiles>

75

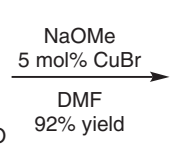<smiles>COc1cc(C(C)C)c(Oc2cnc(N)nc2N)cc1S(N)(=O)=O</smiles>

73

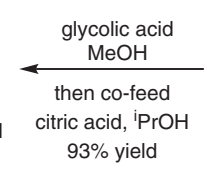

Step $\mathrm{PMI}=20$<smiles>COc1cc(C(C)C)c(Oc2cnc(N)nc2N)cc1S(N)(=O)=O</smiles>

79<smiles>COc1ccc(O)c(C(C)C)c1</smiles>

76

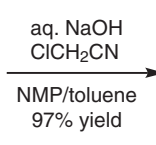

Step PMI $=18$ (from 75 to 77 )<smiles>COc1ccc(OCC#N)c(C(C)C)c1</smiles>

77
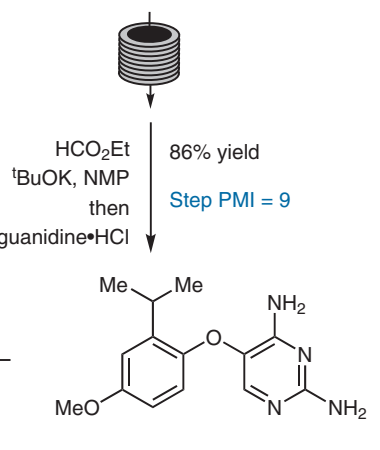

Step PMI $=22$
78

Scheme 23 Supplied process for gefapixant citrate 
The work of the Jamison group ${ }^{63}$ reports on minimizing the E-factor in the flow syntheses of both diazepam and atropine, both identified as essential medicines by World Health Organization. The continuous flow approaches result in a reduction for atropine of 94 -fold (about 2 orders of magnitude) from 2245 to 24 and the E-factor for the synthesis of diazepam was reduced 4 -fold from 36 to 9 . E-factor is defined as the ratio of the mass of waste produced (excluding water) to that of the product obtained. High Efactors indicate large quantities of waste and an environmentally unsustainable process. The main factors which contribute to E-factor include low yield, excess reagents, long multistep synthetic routes, and necessity for extraction or purification using solvents. The E-factor is typically higher with increasing molecular complexity as seen with average E-factors for bulk chemical $(<1-5)$, fine chemical (5-50) and for pharmaceutical industries (25->100)..$^{33}$ The examples noted above showcase how adoption of continuous flow can streamline synthesis to reduce waste production and lower E-factor.

\section{Conclusions and Outlook}

There is little doubt that flow chemistry has had a very positive impact on the way molecular entities are generated today. Obvious advantages such as improvements in heat and mass transfer, process safety and scalability are thereby complemented by reaction automation and thus increased process control. As this short review highlights, improved sustainability can be achieved in each field of synthetic chemistry when suitable approaches are followed. For instance, photochemical transformations are intrinsically green in view of using light as a reagent, however, efforts are needed to optimize solvent and catalyst use to minimize cost and waste generation. Similarly, electrochemical flow processes are attractive and several effective reactor systems have now been reported. Support electrolytes may still be needed, though at significantly reduced amounts, which together with the absence of stoichiometric reagents provides for high sustainability potential. The use of biocatalysts has already impacted the green credentials of many batch processes, and flow processing can further improve on this by increasing mass transfer and expanding the number of compelling case studies affecting both the synthesis and downstream processing of waste materials. Reaction telescoping can significantly add to increased efficiency and safety of flow processes; however, careful balancing of multiple interlinked parameters is vital to avoid unnecessary process complexity. Such fine-tuning may prompt for the use of less green solvents or higher dilutions, and thus may be counterproductive in view of overall sustainability goals. Clearly, judicious choices are required in such cases to define the overall objectives depending on the application in question. In the case of exploiting reactive gases, flow processing has clear advantages over batch processing, and as shown for selected examples based on oxygen and hydrogen gas, related redox processes are not only safer in flow mode, but moreover add to the sustainability of such approaches when combined with innovative transformations.

It is essential for the chemical industry to be externally focused to remain ahead of the game and to embrace technology advancements. Flow chemistry is one such advancement which is now ready for adoption. Horizon scanning will be essential to attempt to predict the market needs including technology pulls with inevitable disruptions being observed over the next decade. Organizations need to anticipate what direction competitors are moving in and identify alliances with others who are set to experience similar disruptions to maintain competitive advantage. To achieve the necessary agility to survive, companies within the pharma sector are in a race to close capability gaps and create strategies to access in-demand resources. Technologies like chemo- and biocatalysis are the norm (and expected). Flow assisted technologies are now becoming more and more prevalent in technical packages received in the industry.

It is envisaged new continuous processes will be brought online as success will bread success. The ability of flow technology to produce hard cost savings for pre-existing processes or to provide novel routes to access new chemical entities (NCEs) is at the forefront of key technologies and investments within the industry. The key difference between flow today and ten years ago is the availability of supporting technologies and multiple companies who can support its further growth.

Flow chemistry is truly a 21 st century technology readily available to all chemists. It brings many benefits, including new route options, process simplification, increased speed of delivery, enhanced safety and control, and the potential to generate new IP to protect your invention. It is time to embrace change and give it a go.

\section{Conflict of Interest}

The authors declare no conflict of interest.

\section{Funding Information}

The authors gratefully acknowledge the financial support from Science Foundation Ireland under the SFI Industry Fellowship programme for the project entitled 'Development of Continuous Biocatalysed Processes - Continuous Biocatalysed Chemicals (CATCH)' (19/IFA/7420, to MB).

\section{References}

(1) (a) Guidi, M.; Seeberger, P. H.; Gilmore, K. Chem. Soc. Rev. 2020 , 49, 8910. (b) Jensen, K. F. AIChE J. 2017, 63, 858. (c) Fitzpatrick, D. E.; Battilocchio, C.; Ley, S. V. ACS Cent. Sci. 2016, 2, 131. 
(d) Gerardy, R.; Emmanuel, N.; Toupy, T.; Kassin, V. E.; Tshibalonza, N. N.; Schmitz, M.; Monbaliu, J.-C. M. Eur. J. Org. Chem. 2018, 2301.

(2) (a) Baumann, M.; Moody, T. S.; Smyth, M.; Wharry, S. Org. Process Res. Dev. 2020, 24, 1802. (b) Ley, S. V.; Chen, Y.; Robinson, A.; Otter, B.; Godineau, E.; Battilocchio, C. Org. Process Res. Dev. 2021, 25, 713. (c) Mallet-Sanz, L.; Susanne, F. J. Med. Chem. 2012, 55, 4062. (d) Gioiello, A.; Piccinno, A.; Lozza, A. M.; Cerra, B. J. Med. Chem. 2020, 63, 6624.

(3) (a) Morin, M. A.; Zhang, W.; Mallik, D.; Organ, M. G. Angew. Chem. Int. Ed. 2021, in press DOI: 10.1002/ange.202102009. (b) Baumann, M. Org. Biomol. Chem. 2018, 16, 5946. (c) Reizman, B. J.; Jensen, K. F. Acc. Chem. Res. 2016, 49, 1786. (d) Haven, J. J.; Junkers, T. Eur. J. Org. Chem. 2017, 6474.

(4) Ley, S. V. Chem. Rec. 2012, 12, 378.

(5) (a) Williams, J. D.; Kappe, C. O. Curr. Opin. Green Sustain. Chem. 2020, 25, 100351. (b) Dallinger, D.; Kappe, C. O. Curr. Opin. Green Sustain. Chem. 2017, 7, 6.

(6) (a) Rogers, L.; Jensen, K. F. Green Chem. 2019, 21, 3481. (b) Newman, S. G.; Jensen, K. F. Green Chem. 2013, 15, 1456.

(7) (a) Aguillón, A. R.; Bezerra, M. A. de M.; Gomez, M. R. B. P.; de Souza, R. O. M. A. Continuous-Flow Chemistry toward Sustainable Chemical Synthesis, In Green Sustainable Process for Chemical and Environmental Engineering and Science; Inamuddin, ; Boddula, R.; Asiri, A. M., Ed.; Elsevier: Amsterdam, 2020, 49-69. (b) Alfano, A. I.; Brindisi, M.; Lange, H. Green Chem. 2021, 23, 2233. (c) Vaccaro, L.; Lanari, D.; Marrocchi, A.; Strappaveccia, G. Green Chem. 2014, 16, 3680.

(8) https://www.chemistryworld.com/features/flow-chemistrysurges-forward/4013358.article (accessed May 29, 2021)

(9) Ciamician, G. Science 1912, 36, 385.

(10) (a) Romero, N. A.; Nicewicz, D. A. Chem. Rev. 2016, 116, 10075. (b) Shaw, M. H.; Twilton, J.; MacMillan, D. W. C. J. Org. Chem. 2016, 81, 6898. (c) Liu, J.; Lu, L.; Wood, D.; Lin, S. ACS Cent. Sci. 2020, 6, 1317.

(11) (a) Sambiago, C.; Nöel, T. Trends Chem. 2020, 2, 92. (b) Di Filippo, M.; Bracken, C.; Baumann, M. Molecules 2020, 25, 356. (c) Rehm, T. H. Chem. Eur. J. 2020, 26, 16952.

(12) (a) Kayahan, E.; Jacobs, M.; Braeken, L.; Thomassen, L. C. J.; Kuhn, S.; van Gerven, T.; Leblebici, M. E. Beilstein J. Org. Chem. 2020, 16, 2484. (b) Donnelly, K.; Baumann, M. J. Flow Chem. 2021, in press DOI: 10.1007/s41981021-00168-z.

(13) Proctor, R. S. J.; Phipps, R. J. Angew. Chem. Int. Ed. 2019, 58, 13666.

(14) (a) Beatty, J. W.; Douglas, J. J.; Cole, K. P.; Stephenson, C. R. J. Nat. Commun. 2015, 6, 7919. (b) Beatty, J. W.; Douglas, J. J.; Miller, R.; McAtee, R. C.; Cole, K. P.; Stephenson, C. R. J. Chem 2016, 1, 456.

(15) Abdiaj, I.; Bottecchia, C.; Alcazar, J.; Nöel, T. Synthesis 2017, 49, 4978.

(16) Hyowon, S.; Aofei, L.; Jamison, T. F. J. Am. Chem. Soc. 2017, 139, 13969.

(17) For selected examples, please see: (a) Emmanuel, N.; Mendoza, C.; Winter, M.; Horn, C. R.; Vizza, A.; Dreesen, L.; Heinrichs, B.; Monbaliu, J.-C. M. Org. Process Res. Dev. 2017, 21, 1435. (b) Kong, C. J.; Fisher, D.; Desai, B. K.; Yang, Y.; Ahmad, S.; Belecki, K.; Gupton, B. F. Bioorg. Med. Chem. 2017, 25, 6203. (c) Lee, D. S.; Sharabi, M.; Jefferson-Loveday, R.; Pickering, S. J.; Poliakoff, M.; George, M. W. Org. Process Res. Dev. 2020, 24, 201.

(18) Schultz, D. M.; Lévesque, F.; DiRocco, D. A.; Reibarkh, M.; Ji, Y.; Joyce, L. A.; Dropinski, J. F.; Sheng, H.; Sherry, B. D.; Davies, I. W. Angew. Chem. Int. Ed. 2017, 56, 15274.
(19) Laudadio, G.; Govaerts, S.; Wang, Y.; Ravelli, D.; Koolman, H. F.; Fagnoni, M.; Djuric, S. W.; Noël, T. Angew. Chem. Int. Ed. 2018, $57,4078$.

(20) Bonciolini, S.; Di Filippo, M.; Baumann, M. Org. Biomol. Chem. 2020, $18,9428$.

(21) Laudadio, G.; Deng, Y.; van der Wal, K.; Ravelli, D.; Nuño, M.; Fagnoni, M.; Guthrie, D.; Sun, Y.; Noël, T. Science 2020, 369, 92.

(22) Donnelly, K.; Baumann, M. Chem. Commun. 2021, 57, 2871.

(23) Kingston, C.; Palkowitz, M. D.; Takahira, Y.; Vantourout, J. C.; Peters, B. K.; Kawamata, Y.; Baran, P. S. Acc. Chem. Res. 2020, 53, 72.

(24) Nöel, T.; Cao, Y.; Laudadio, G. Acc. Chem. Res. 2019, 52, 2858.

(25) Tanbouza, N.; Ollevier, T.; Lam, K. iScience 2020, 23, 101720.

(26) Folgueiras-Amador, A. A.; Philipps, K.; Guilbaud, S.; Poelakker, J.; Wirth, T. Angew. Chem. Int. Ed. 2017, 56, 15446.

(27) Santi, M.; Seitz, J.; Cicala, R.; Hardwick, T.; Ahmed, N.; Wirth, T. Chem. Eur. J. 2019, 25, 16230.

(28) Vilé, G.; Schmidt, G.; Richard-Bildstein, S.; Abele, S. J. Flow Chem. 2019, 9, 19.

(29) Laudadio, G.; Barmpoutsis, E.; Schotten, C.; Struik, L.; Govaerts, S.; Browne, D. L.; Nöel, T. J. Am. Chem. Soc. 2019, 141, 5664.

(30) Selt, M.; Franke, R.; Waldvogel, S. R. Org. Process Res. Dev. 2020, $24,2347$.

(31) (a) Britton, J.; Majumdar, S.; Weiss, G. A. Chem. Soc. Rev. 2018, 47, 5891. (b) Benítez-Mateos, A. I.; Contente, M. L.; Padrosa, D. R.; Paradisi, F. React. Chem. Eng. 2021, 6, 599. (c) De Santis, P.; Meyer, L.-E.; Kara, S. React. Chem. Eng. 2020, 5, 2155. (d) Santi, M.; Sancineto, L.; Nascimento, V.; Braun Azeredo, J.; Orozco, E. V. M.; Andrade, L. H.; Gröger, H.; Santi, C. Int. J. Mol. Sci. 2021, 22, 990.

(32) (a) Planchestainer, M.; Contente, M. L.; Cassidy, J.; Molinari, F.; Tamborini, L.; Paradisi, F. Green Chem. 2017, 19, 372. (b) Andrade, L. H.; Kroutil, W.; Jamison, T. F. Org. Lett. 2014, 16, 6092. (c) Ho, C.-H.; Yi, J.; Wang, X. ACS Sustainable Chem. Eng. 2019, 7, 1038. (d) Contente, M. L.; Dall'Oglio, F.; Tamborini, L.; Molinari, F.; Pardisi, F. ChemCatChem 2017, 9, 1.

(33) Federsel, H.-J.; Moody, T. S.; Taylor, S. J. C. Molecules 2021, 26, 2822.

(34) Xiao, Y.; Zheng, M.; Liu, Z.; Shi, J.; Huang, F.; Luo, X. ACS Sustainable Chem. Eng. 2019, 7, 2056.

(35) Goldhahn, C.; Taut, J. A.; Schubert, M.; Burgert, I.; Chanana, M. RSC Adv. 2020, 10, 20608.

(36) (a) Leslie, A.; Moody, T. S.; Smyth, M.; Wharry, S.; Baumann, M. Beilstein J. Org. Chem. 2021, 17, 379. (b) Baumann, M.; Leslie, A.; Moody, T. S.; Smyth, M.; Wharry, S. Org. Process Res. Dev. 2021, $25,452$.

(37) (a) Britton, J.; Raston, C. L. Chem. Soc. Rev. 2017, 46, 1250. (b) Jiao, J.; Nie, W.; Yu, T.; Yang, F.; Zhang, Q.; Aihemaiti, F.; Yang, T.; Liu, X.; Wang, J.; Li, P. Chem. Eur. J. 2021, 27, 4817.

(38) Britton, J.; Jamison, T. F. Angew. Chem. Int. Ed. 2017, 56, 8823.

(39) Lin, H.; Dai, C.; Jamison, T. F.; Jensen, K. F. Angew. Chem. Int. Ed. 2017, 56, 8870.

(40) Kassin, V.-E. H.; Gerardy, R.; Toupy, T.; Collin, D.; Salvadeo, E.; Toussaint, F.; Van Hecke, K.; Monbaliu, J.-C. M. Green Chem. 2019, 21, 2952.

(41) Di Filippo, M.; Baumann, M. Eur. J. Org. Chem. 2020, 6199.

(42) (a) Mallia, C. J.; Baxendale, I. R. Org. Process Res. Dev. 2016, 20, 327. (b) Brzozowski, M.; O’Brien, M.; Ley, S. V.; Polyzos, A. Acc. Chem. Res. 2015, 48, 349. (c) Hone, C. A.; Kappe, C. O. Eur. J. Org. Chem. 2020, 13108. (d) Hone, C. A.; Kappe, C. O. Top. Curr. Chem. 2019, 377, 2.

(43) Pye, S. J.; Dalgarno, S. J.; Chalker, J. M.; Raston, C. L. Green Chem. 2018, 20, 118. 
(44) Guo, S.; Yu, Z.; Yu, C. Org. Process Res. Dev. 2018, 22, 252.

(45) Saito, Y.; Kobayashi, S. J. Am. Chem. Soc. 2020, 142, 16546.

(46) Prieschl, M.; Garcia-Lacuna, J.; Munday, R.; Leslie, K.; O'Kearney-McMullan, A.; Hone, C. A.; Kappe, C. O. Green Chem. 2020, 22, 5762.

(47) https://ec.europa.eu/environment/chemicals/reach/reach_en.htm (accessed August 9, 2021)

(48) https://www.forbes.com/sites/cognitiveworld/2020/12/26/theincreasing-use-of-ai-in-the-pharmaceutical-industry/ (accessed August 9, 2021)

(49) https://assets.kpmg/content/dam/kpmg/uk/pdf/2019/04/reshapingthe-future-of-pharma.pdf (accessed August 9, 2021)

(50) Scott, M. New York Times, July 15, 2014 (accessed August 9, 2021); https://www.nytimes.com/2014/07/16/business/international/novartisjoins-with-google-to-develop-contact-lens-to-monitor-bloodsugar.html

(51) Roger, L.; Jensen, K. F. Green Chem. 2019, 21, 3481.

(52) Sheldon, R. A. ACS Sustainable Chem. Eng. 2018, 6, 32.

(53) Sheldon, R. A. Green Chem. 2007, 9, 1273.

(54) Sheldon, R. A. Green Chem. 2017, 19, 18.
(55) Falß, S.; Kloye, N.; Holtkamp, M. L.; Prokofyeva, A.; Bieringer, T.; Kockmann, N. Green Chemical Engineering, In Handbook of Green Chemistry, Vol. 12; Lapkin, A., Ed.; Wiley-VCH: Weinheim, 2019, 153.

(56) Amini-Rentsch, L.; Vanoli, E.; Richard-Bildstein, S.; Marti, R.; Vile, G. Ind. Eng. Chem. Res. 2019, 58, 10164.

(57) Das, P.; Delost, M. D.; Qureshi, M. H.; Smith, D. T.; Njardarson, J. T. J. Med. Chem. 2019, 62, 4265.

(58) Taylor, R. D.; MacCoss, M.; Lawson, A. D. G. J. Med. Chem. 2014, $57,5845$.

(59) Larock, R. C.; Babu, S. Tetrahedron Lett. 1987, 28, 5291.

(60) Schafer, G.; Ahmetovic, M.; Abele, S. Org. Lett. 2017, 19, 6578.

(61) Ren, H.; Maloney, K. M.; Basu, K.; Di Maso, M. J.; Humphrey, G. R.; Peng, F.; Desmond, R.; Otte, D. A. L.; Alwedi, E.; Liu, W.; Zhang, S.-W.; Song, S.; Arvary, R. A.; Zompa, M. A.; Lehnherr, D.; Martin, G. E.; Chang, H. Y. D.; Mohan, A. E.; Guzman, F. J.; Jellet, L.; Lee, A. Y.; Spencer, G.; Fisher, E. S.; Naber, J. R.; Gao, H.; Lohani, S.; Ruck, R. T.; Campeau, L.-C. Org. Process Res. Dev. 2020, 24, 2445.

(62) Dvorak, C. A.; Green, K. L.; Lee, G. R. WO 2008040652, 2008.

(63) Bedard, A.-C.; Longstreet, A. R.; Britton, J.; Wang, Y.; Moriguchi, H.; Hicklin, R. W.; Green, W. H.; Jamison, T. F. Bioorg. Med. Lett. 2017, 25, 6233. 